\title{
Molecular and serological evidence for the circulation of the tick symbiont Midichloria (Rickettsiales: Midichloriaceae) in different mammalian species
}

Chiara Bazzocchi ${ }^{1}$, Mara Mariconti ${ }^{2}$, Davide Sassera ${ }^{1}$, Laura Rinaldi ${ }^{3}$, Elena Martin', Giuseppe Cringoli ${ }^{3}$ Sandra Urbanelli ${ }^{4}$, Claudio Genchi ${ }^{1}$, Claudio Bandi ${ }^{1}$ and Sara Epis ${ }^{1 *}$

\begin{abstract}
Background: The Midichloriaceae is a novel family of the order Rickettsiales, that encompasses intracellular bacteria associated with hard ticks (Ixodidae) and other arthropods. The most intensively investigated member of this family is Midichloria mitochondrii, a symbiotic bacterium of the sheep tick Ixodes ricinus, characterized by the capacity of multiplying inside the mitochondria. A recent study suggested that these bacteria might be inoculated into the human host during the tick bite. The purpose of this study was to determine the potential infectivity of Midichloria bacteria for non-human animals exposed to the risk of tick bite.

Methods: Blood from horses, cattle, sheep and dogs exposed to the risk of tick bite was included in this study. DNAs were extracted, and amplified using $16 \mathrm{~S}$ ribosomal RNA primers conserved in the Midichloria genus.

Furthermore, sera from dogs exposed to the risk of tick bite were analyzed in order to evaluate the presence of antibodies against the recombinant flagellar protein (rFliD) from M. mitochondrii using an ELISA test.

Results: Here we present two lines of evidence that support the possibility that bacteria from the genus Midichloria are inoculated into vertebrate hosts during a tick bite: (i) a direct evidence, i.e. the detection of circulating DNA from bacteria related with M. mitochondrii, in the blood of vertebrates exposed to tick parasitism; (ii) a further indirect evidence, i.e. the presence of antibodies against an antigen from M. mitochondrii in dogs exposed to the risk of tick bite. It is interesting to note that variability was detected in the Midichloria gene sequences recovered from positive animals, and that some of these sequences were identical to those generated from tick-associated Midichloria.

Conclusions: Based on the results, and on the overall information so far published on the genus Midichloria, we suggest that these bacteria are likely to represent a novel group of vector-borne agents, with the potential of infecting mammalian hosts. Whether inoculation of Midichloria bacteria could cause a true infection and pathological alteration in mammalian hosts is still to be determined. Surely, results emphasize the relevance of Midichloria bacteria in investigations on tick immunology and tick-bite markers.
\end{abstract}

Keywords: Midichloria, Ticks, Mammalian hosts, Emerging infections, Vector-borne diseases

\footnotetext{
*Correspondence: sara.epis@guest.unimi.it

'Dipartimento di Scienze Veterinarie e Sanità Pubblica, Università degli Studi

di Milano, Milano, Italy

Full list of author information is available at the end of the article
} 


\section{Background}

Ticks are responsible for the transmission of a number of bacterial, protozoan and viral diseases to humans and animals. In addition to well-established pathogenic bacteria, ticks frequently harbour microorganisms whose pathogenic role to vertebrates is still to be determined; some of these have been regarded as symbionts, capable of providing the host tick with some fitness advantage [1,2]. A recently described family of the Rickettsiales, Candidatus Midichloriaceae (hereafter Midichloriaceae), encompasses a wide group of intracellular bacteria associated with ticks [3,4]. The most intensively investigated member of the family Midichloriaceae is Candidatus Midichloria mitochondrii (hereafter M. mitochondrii), an intracellular bacterial symbiont that is widespread in the hard tick Ixodes ricinus $[5,6]$, the main vector of Lyme disease in Europe. M. mitochondrii is present both in the cell cytoplasm and within the inter-membrane space of mitochondria in the ovary of the host tick $[7,8]$. Other ticks that have been shown to harbour bacteria attributable to the genus Midichloria include members of the genera Ixodes, Rhipicephalus, Amblyomma, Hyalomma and Dermacentor [3,9,10].

Recently, M. mitochondrii has been detected in the salivary glands of $I$. ricinus, and human patients parasitized by this tick have been shown to be seropositive toward an antigenic protein from this bacterium [11]. M. mitochondrii can thus be regarded not only as a symbiont of $I$. ricinus, but also as a potential infectious agent or, at least, as a package of antigens that ticks likely inject into the vertebrate hosts during the blood meal. The fate of $M$. mitochondrii in the vertebrate after the tick bite is indeed still unexplored, but there is circumstantial evidence for the presence of circulating DNA from $M$. mitochondrii in roe deer (as revealed during a screening for Anaplasma phagocytophilum in Denmark [12]). In addition, DNA from another bacterium of the family Midichloriaceae (known as 'Montezuma') was detected in human patients parasitized by Ixodes persulcatus [13]. Despite this circumstantial evidence, no systematic studies have so far been focused on the specific goal of determining whether DNA from bacteria of the genus Midichloria can be detected in blood samples from animals exposed to tick parasitism. In addition, no evidence has so far been published for the presence of antiMidichloria antibodies in the sera from animals other than Homo sapiens. The goals of this work were thus to determine: i) whether circulating DNA from Midichloria bacteria is detectable in animals exposed to the risk of tick bite; ii) whether dogs exposed to the risk of tick parasitism are seropositive for anti-Midichloria antibodies.

\section{Methods}

\section{Sample collection}

One hundred fifty-six whole blood samples from different mammalian hosts exposed to the risk of tick bite were included in the study: 46 horses, 13 cattle and 11 sheep from non-intensive breeding farms, in which animals are allowed to graze out of the stable for 3-6 months during the year, in the regions Lombardia and Lazio, Italy; 62 dogs, form a kennel in Pantelleria Island, Italy; 4 dogs from a kennel in the Molise region, Italy; 20 dogs from two kennels in the Campania region, Italy (Table 1). In order to examine animals at low risk of tick bite, blood from 30 cattle from an intensive dairy farm and from 20 experimental dogs that had been collected in the context of a previous study [14], were included in the analyses. DNA from blood samples was extracted by using the QIAamp DNA blood mini kit (Qiagen, Hilden, Germany) according to the manufacturer's instructions, eluted into $100 \mu \mathrm{l}$ of sterile water and stored at $-20^{\circ} \mathrm{C}$ until use. For serological analysis, a total of 218 dog sera were collected from 16 kennels (hereafter indicated as K1-K16) located in southern Italy (Table 2 ) and stored at $-20^{\circ} \mathrm{C}$ until use. Sera from the above 20 experimental dogs were used as control samples also for serology.

\section{PCR analysis}

DNAs extracted from blood samples were analyzed for the presence of circulating DNA from $M$. mitochondrii or

Table 1 Animals screened for the presence of circulating Midichloria DNA

\begin{tabular}{|c|c|c|c|}
\hline Mammalian host & Region or origin & Sample size & No. of positive (\%) \\
\hline$\overline{D o g}\left(K p^{a}\right)$ & Sicilia & 62 & $18(29 \%)$ \\
\hline $\operatorname{Dog}\left(K 1^{b}\right)$ & Molise & 4 & $1(25 \%)$ \\
\hline $\operatorname{Dog}\left(K 3^{b}\right)$ & Campania & 7 & $1(14 \%)$ \\
\hline $\operatorname{Dog}\left(K 14^{b}\right)$ & Campania & 13 & $0(0 \%)$ \\
\hline Horse $\left(\mathrm{NI}^{\mathrm{C}}\right)$ & Lazio & 46 & $5(11 \%)$ \\
\hline Sheep $\left(\mathrm{NI}^{\mathrm{C}}\right)$ & Lombardia & 11 & $1(9 \%)$ \\
\hline Cattle $\left(\mathrm{NI}^{\mathrm{C}}\right)$ & Lombardia & 13 & $0(0 \%)$ \\
\hline Cattle $\left(I^{d}\right)$ & Lombardia & 30 & $0(0 \%)$ \\
\hline Dog (control group) & Experimental animals $\mathrm{e}^{\mathrm{e}}$ & 20 & $0(0 \%)$ \\
\hline
\end{tabular}

${ }^{a}$ dogs from a kennel in the Pantelleria Island (Kp), Sicilia; ${ }^{b}$ kennel code as indicated in Table 2 ; Canimals from non-intensive (NI) breeding farms; ${ }^{d}$ animals from an intensive (I) breeding farm; ${ }^{\mathrm{e}}$ animals from a previous experimental study [14]. 
Table 2 Dogs screened for the presence of anti-Midichloria antibodies

\begin{tabular}{|c|c|c|c|c|}
\hline Kennel code or group & County or origin & No. of dogs & Positivity $^{a}$ & OD average \pm SD (OD min-OD max) \\
\hline $\mathrm{K} 1$ & Campobasso & 15 & 86.6 & $0.46 \pm 0.2(0.22-0.8)$ \\
\hline K2 & Salerno & 16 & 31.25 & $0.25 \pm 0.07(0.18-0.36)$ \\
\hline K3 & Avellino & 19 & 73.68 & $0.33 \pm 0.1(0.2-0.53)$ \\
\hline K4 & Avellino & 9 & 22.2 & $0.27 \pm 0.16(0.17-0.6)$ \\
\hline K5 & Avellino & 9 & 55.5 & $0.27 \pm 0.09(0.19-0.48)$ \\
\hline K6 & Avellino & 13 & 61.53 & $0.27 \pm 0.08(0.15-0.42)$ \\
\hline K7 & Napoli & 12 & 8.3 & $0.14 \pm 0.08(0.1-0.32)$ \\
\hline K8 & Caserta & 13 & 23 & $0.14 \pm 0.12(0.07-0.38)$ \\
\hline K9 & Avellino & 15 & 20 & $0.20 \pm 0.09(0.09-0.39)$ \\
\hline K10 & Caserta & 19 & 5.26 & $0.14 \pm 0.06(0.09-0.35)$ \\
\hline K11 & Napoli & 16 & 12.5 & $0.16 \pm 0.05(0.08-0.27)$ \\
\hline $\mathrm{K} 12$ & Avellino & 12 & 8.3 & $0.16 \pm 0.08(0.1-0.4)$ \\
\hline K13 & Napoli & 16 & 0 & $0.12 \pm 0.03(0.09-0.17)$ \\
\hline K14 & Avellino & 13 & 0 & $0.15 \pm 0.04(0.1-0.24)$ \\
\hline K15 & Salerno & 16 & 0 & $0.13 \pm 0.2(0.05-0.1)$ \\
\hline K16 & Napoli & 5 & 0 & $0.12 \pm 0.06(0.08-0.22)$ \\
\hline Control & Exp. animals ${ }^{b}$ & 20 & 5 & $0.13 \pm 0.05(0.07-0.28)$ \\
\hline
\end{tabular}

apercentage of positive animals, based on the cut-off determined on the basis of the results from control dogs (see Methods); ${ }^{\mathrm{b}}$ animals from a previous experimental study [14].

related bacteria, using a previously described PCR protocol, with primers designed on the gene coding for the $16 \mathrm{~S}$ ribosomal RNA (16S rDNA) and targeted on portions of this gene that are conserved among representatives of the genus Midichloria [3,9]. All of the DNAs from blood samples were also examined using universal mammalian PCR primers, targeted on the $12 \mathrm{~S}$ rRNA gene [15]. PCR products obtained with Midichloria primers were sequenced using ABI technology, and compared with the databases using BLAST (National Center for Biotechnology Information, Bethesda, Md). Seven of the obtained 16S rDNA sequences were deposited in the data bases (see Figure 1 for the accession numbers), with only one sequence deposited from each host species where the sequences from that host were identical.

\section{Phylogenetic reconstruction}

The 16S rDNA sequences generated were aligned with the corresponding sequences from Midichloriaceae bacteria, including Rickettsia rickettsii as an outgroup. In addition, a sub-alignment was generated including sequences representative of the Midichloriaceae genera Midichloria and Lariskella. The alignment was generated using MUSCLE [16] and manually checked. Phylogenetic analysis were effected using the Neighbor joining method after Kimura 2parameter correction or Jukes and Cantor correction, after either including or excluding the insertion/deletions, or using maximum likelihood with GTR substitution model. Phylogenetic analyses were performed using SeaView [17], estimating the reliability of the nodes after 100 bootstrap replicates.

\section{ELISA analysis}

The recombinant flagellar protein FliD of $M$. mithocondrii (rFliD) was produced in Escherichia coli and purified as described in Mariconti et al. [18]. Wells of ELISA flat-bottom plates were coated with $0.1 \mu \mathrm{g} /$ well of rFliD. Sera were analyzed in duplicate at a dilution of 1:100 and the anti IgG HRP-conjugated antibody was employed at 1:5000. The optical density (O.D.) was measured at a wavelength of $492 \mathrm{~nm}$. The cut-off was established at an O.D. of 0.25, which is the mean O.D. of the 20 control sera plus three times their standard deviation. Samples with O.D. lower than 0.25 were classified as negative and samples with O.D. greater than or equal to 0.25 were classified as positive.

\section{Ethical statement}

The study was approved from the National Ethics Committee of the involved institutes.

\section{Results and discussion}

This work presents the first screening aimed at detecting DNA from tick-associated Midichloriaceae bacteria in mammalians. A total of 156 blood samples derived from horses, cattle, sheep and dogs at risk of tick bite were analyzed by PCR, using a previously described PCR protocol targeted on the $16 \mathrm{~S}$ rDNA gene of $M$. mitochondrii and related bacteria [9]. Blood samples from 30 cattle and 20 


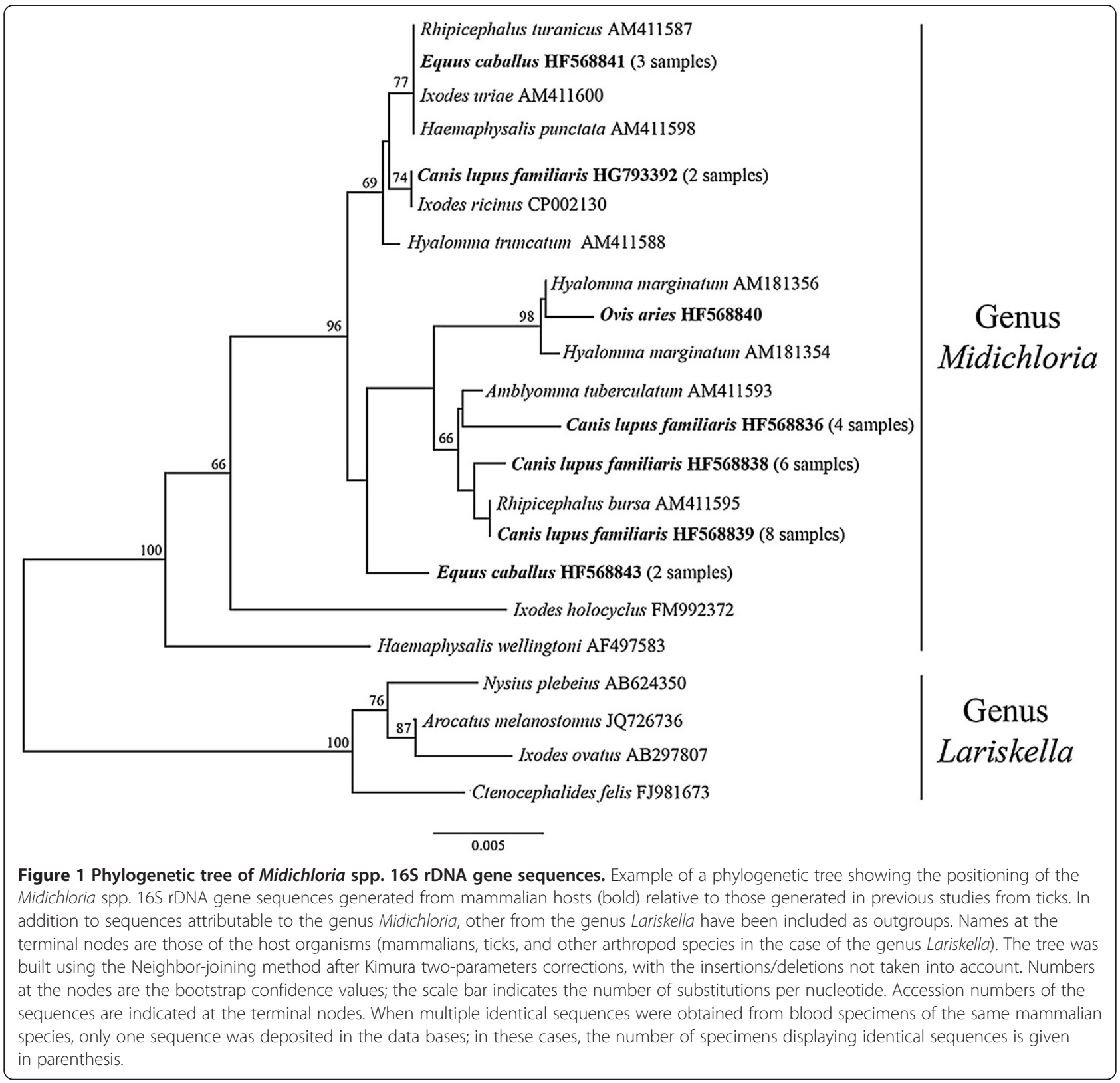

dogs that are regarded as having no or limited risk of tick bite were also included. Details on the different groups of animals examined are listed in Table 1.

The quality of the DNAs extracted was checked by PCR using universal mammalian primers targeted on the mitochondrial 12S rRNA gene that led to positive amplification from all samples. Midichloria-targeted primers led to positive amplification from 26 of the animals at risk of tick bite, and from none of the control animals (Table 1). The animal species that presented the higher prevalence of positive animals was the dog, where 20 out of 86 animals were positive. Eighteen of these dogs were hosted in a kennel in the Pantelleria island (part of the Sicily region), where a dense population of the hard tick Rhipicephalus bursa has been recorded (Epis S., personal observation), while two dogs where hosted in two kennels in the Molise and in the Campania regions (Italy). The PCR products obtained from all Midichloria-positive animals (five horses, one sheep, twenty dogs) were recovered from the gel, purified and sequenced by $\mathrm{ABI}$ technology; the obtained sequences were manually corrected, compared with the databases using Blast, and included into different alignments with homologous sequences, for phylogenetic analyses. All of the sequences generated gave the best scores toward 16S rDNA sequences from Midichloriaceae bacteria. Phylogenetic analyses further confirmed that the sequenced PCR products derived from bacteria closely related with M. mitochondrii. In particular, in phylogenetic analyses 
including all of the sequences available from Midichloriaceae bacteria, the sequences here obtained from mammalians were placed into cluster 2 of this family (result not shown), which corresponds to the genus Midichloria [3]. Figure 1 presents an example of a phylogenetic tree obtained including representatives from the two main genera of the Midichloriaceae, Midichloria and Lariskella: the gene fragments generated from the blood samples here examined cluster with those of Midichloria bacteria previously detected in ticks (trees generated using different settings/algorithms presented the same placement for Midichloria sequences derived from blood samples). It has already been shown that Midichloria bacteria harbored by different tick species are variable at the level of the $16 \mathrm{~S}$ rDNA [9].

The tree in Figure 1 shows that the novel sequences from mammalians are in some cases identical to those obtained from ticks: sequences from three horses to those obtained from three different tick species (Ixodes uriae, Haemaphysalis punctata and Rhipicephalus turanicus; sequences published in ref. [9]); sequences from eight dogs from the Pantelleria island to those obtained from $R$. bursa [9]; sequences from two dogs from the Molise and Campania regions to those obtained from I. ricinus [6]. Other $16 \mathrm{~S}$ rDNA gene sequences obtained from the examined mammalians differ from those so far generated from ticks (showing from 2 to 5 nucleotide substitutions from the closest $16 \mathrm{~S}$ rDNA Midichloria sequence from ticks). This result is not surprising, considering that only a minimal proportion of the ticks present in Italy have been screened for Midichloria bacteria [9]; the overall molecular diversity of these bacteria is thus still to be determined. In summary, we can affirm that DNA from bacteria attributable to the genus Midichloria can be detected in the blood of different animal species, and, in at least a few of the cases here examined, we can reasonably hypothesize that the origin of the detected DNA could be traced to ticks. For example, $R$. bursa, I. ricinus and $R$. turanicus could be involved in the transmission of Midichloria bacteria (or their DNA) to dogs and horses, also considering the host spectrum of these tick species and/or their distribution in the areas where the blood samples were collected $[19,20]$ (e.g. the case of $R$. bursa in the Pantelleria island and of $I$. ricinus in the Molise and Campania regions).

The above results prompted us to develop an ELISA test to screen sera for indirect signs of infection by $M$. mitochondrii, focusing the study on the dog; this test was based on a recombinant antigen from $M$. mitochondrii, the flagellar protein $\mathrm{rFliD}[11,18]$. We emphasize that we do not expect cross-reactivity of this antigen toward tickassociated spirochetes, Rickettsiaceae or Anaplasmataceae; rather, cross-reactivity with other bacteria from the family Midichloriaceae cannot be excluded (see discussion below). Using this test we analyzed 218 dog sera collected from 16 kennels located in southern Italy (Table 2), and the sera from the 20 experimental dogs included as controls. The cut-off of the test was determined on the basis of results obtained from the sera from the control dogs, and positioned at 0.25 O.D. As shown in Table 2, the average O.D. values for IgG antibodies reacting with $\mathrm{rFliD}$ is above/equal to the cut-off in K1-6. In these six kennels the percentage of positive dogs ranges from $22.2 \%$ to $86.6 \%$. In the remaining 10 kennels, the average O.D. value was below the 0.25 cut-off: dogs from four of these were all negative (K13-16), while some positive dogs were recorded in the remaining six, as indicated by the O.D. maximum value (K7-12; Table 2).

Considering the whole population of the dogs examined from the 16 kennels, seroprevalence is $26.6 \%$, which is significantly different from the $5 \%$ seroprevalence of control dogs (Student t-test, $\mathrm{P}<0.05$ ). The 218 dogs from the kennels can generally be assumed to be at risk of tick bite, while the 20 experimental dogs can be assumed to have no risk of tick parasitism. Considering the above information, the results here reported (i.e. 26.6\% seroprevalence for M. mitochondrii in dogs at risk of tick bite, and 5\% in dogs at no risk) are congruent with the idea that antigens from M. mitochondrii (or from closely related bacteria) are inoculated into animals during the tick blood meal. As for the differences in the seroprevalence in dogs from the different kennels (Table 2), this could derive from management/sanitary differences among kennels, as well as from their geographic and environmental location, in relation with tick distribution in Italy. For example, in the rural environments of the Molise region, dense populations of $I$. ricinus have been recorded (Rinaldi L., unpublished observations); this can explain the $86.6 \%$ seroprevalence recorded in $\mathrm{K} 1$ (see Table 2), also considering that positivity for M. mitochondrii is $100 \%$ in all the life stages of $I$. ricinus, excluding adult males [5]. In addition, all of the kennels displaying an average O.D. above the cut-off (Table 2, K1-6) are located in rural areas, where tick presence has been recorded [21,22] (Rinaldi L., unpublished observations). On the other hand, the presence of ticks is more sporadic in the urban and suburban environments of Napoli, Salerno and Avellino counties, where kennels displaying lower O.D./seroprevalence values (K7-16) are located $[21,22]$. For only three of the kennels that were included in the serological screening we could collect, for a subsample of the dogs, whole blood for DNA extraction/ PCR screening, in addition to sera samples (K1, K3 and K14; see Tables 1 and 2). In the case of $K 1$ and $K 3$, one PCR positive dog was detected in each kennel (K1, one out of four; K3, one out of seven; see Table 1); the O.D. values for these two PCR-positive dogs were respectively 0.67 and 0.37 , i.e. both of them can be classified as seropositive for $M$. mitochondrii. Being based on a subsample, the above results do not, however, allow us to estimate 
any correlation between serological and PCR positivity. It is anyway interesting that the two kennels where serological positivity is higher present PCR-positive dogs (K1 and K3), while no positive dog was detected in a kennel where all of the animals are seronegative for $M$. mitochondrii (K14).

The antigen used for the above ELISA screening (i.e. rFliD) is a component of the flagellum of $M$. mitochondrii from I. ricinus. This bacterium is rather peculiar in that it is the sole Rickettsiales so far shown to possess a flagellar structure: the well-established pathogenic Rickettsiales form the genera Rickettsia, Ehrlichia and Anaplasma do not have flagella [23]. We would thus exclude that results of the above serological screening derived from crossreactivity with antigens from other Rickettsiales. On the other hand, Borrelia burgdorferi sensu lato, the main pathogen transmitted by Ixodes ticks, does possess immunogenic flagella. However, published results show that, in humans exposed to tick bite, a high proportion of the subjects positive to $M$. mitochondrii are negative to $B$. burgdorferi (and vice-versa), indicating the absence of immunological cross-reactivity among the FliD proteins of Midichloria and Borrelia bacteria [11]. On the other hand, cross-reactivity of rFliD could be expected toward other bacteria from the genus Midichloria, under the reasonable assumption that other bacteria from this genus possess the flagellar gene $f l i D$.

The work reported here presents two lines of evidence that suggest that Midichloria bacteria circulate in mammalians: 1) direct signs of their presence, i.e. the detection of DNA gene fragments in blood samples from different animal species, that cluster in the Midichloria bacterial genus; 2) indirect signs of their presence, i.e. the detection of anti-Midichloria antibodies in dog sera. These results do not of course allow us to infer any conclusion about whether Midichloria bacteria replicate in mammalian hosts: ticks (or other arthropods) might simply inoculate Midichloria (or DNA/proteins from these bacteria), in an amount sufficient for PCR detection and to stimulate antibody production. However, considering the amount of blood in the animals here examined (e.g. horses), we believe it would be unlikely that bacterial DNA inoculated by a few ticks, and diluted into liters of blood, could then be detected by PCR, by the analysis of the DNA extracted from 100 microliters of blood, in the absence of a multiplication in the animal host. We are thus more prone to consider the possibility that Midichloria bacteria multiply in the mammalian host. As for the antibody response toward the rFliD Midichloria antigen, repeated inoculations of antigens from Midichloria by several ticks, as it might occur in animals, could be sufficient to stimulate an antibody response. On the other hand, the seropositivity for Midichloria recorded in humans parasitized by ticks is suggestive of a replication of these bacteria, considering that single ticks had generally been removed from the examined subjects, normally after a very short blood meal [11].

\section{Conclusions}

In summary, our current work on animals, together with the previously published study on humans [11], presents overall evidence that ticks inoculate Midichloria bacteria into mammalian hosts during the blood meal, and that these bacteria likely multiply, inducing an antibody response. Whether inoculation of Midichloria bacteria could lead to the infection of the host, and whether this could determine pathological alterations, is now a main research issue. In addition, investigations on the immunology of the tick saliva [24] should now take into account the possible presence and potential immunomodulatory activity of Midichloria and Midichloria-associated molecules.

\section{Competing interests}

The authors declare that they have no competing interests.

\section{Authors' contributions}

CHB, CLB and SE conceived the study and contributed to data analysis, interpretation and manuscript writing. MM, SE and EM performed the molecular and serological analyses; LR, GC and CG contributed to sample collection. DS and SU performed the phylogenetic analysis and contributed to data interpretation and manuscript writing. All authors read and approved the final version of the manuscript.

\section{Acknowledgements}

Work partially supported by MIUR Prin 2009 (to CLB) and MIUR Prin 2010-2011 (to CG). We thank L. Ferretti and A. Bagnato for providing blood samples from cattle.

\section{Author details}

'Dipartimento di Scienze Veterinarie e Sanità Pubblica, Università degli Studi di Milano, Milano, Italy. ${ }^{2}$ Fondazione IRCCS Policlinico San Matteo, Pavia, Italy. ${ }^{3}$ Dipartimento di Patologia e Sanità Animale, Università degli Studi di Napoli Federico II, Napoli, Italy. ${ }^{4}$ Dipartimento di Biologia Ambientale, Università di Roma La Sapienza, Roma, Italy.

Received: 4 July 2013 Accepted: 6 December 2013

Published: 12 December 2013

\section{References}

1. Raoult D, Roux V: Rickettsioses as paradigms of new or emerging infectious diseases. Clin Microbiol Rev 1997, 10:694-719.

2. Taylor M, Mediannikov O, Raoult D, Greub G: Endosymbiotic bacteria associated with nematodes, ticks and amoebae. Fems Immunol Med Microbiol 2012, 64:21-31

3. Montagna M, Sassera D, Epis S, Bazzocchi C, Vannini C, Lo N, Sacchi L, Fukatsu T, Petroni G, Bandi C: "Candidatus Midichloriaceae" fam. nov. (Rickettsiales), an ecologically widespread clade of intracellular Alphaproteobacteria. Appl Environ Microbiol 2013, 79:3241-3248.

4. Driscoll T, Gillespie JJ, Nordberg EK, Azad AF, Sobral BW: Bacterial DNA sifted from the Trichoplax adhaerens (Animalia: Placozoa) genome project reveals a putative rickettsial endosymbiont. Genome Biol Evol 2013, 5:621-645.

5. Lo N, Beninati T, Sassera D, Bouman EAP, Santagati S, Gern L, Sambri V, Masuzawa T, Gray JS, Jaenson TGT, Bouattour A, Kenny MJ, Guner ES, Kharitonenkov IG, Bitam I, Bandi C: Widespread distribution and high prevalence of an alpha-proteobacterial symbiont in the tick Ixodes ricinus. Environ Microbiol 2006, 8:1280-1287.

6. Sassera D, Beninati T, Bandi C, Bouman EAP, Sacchi L, Fabbi M, Lo N: "Candidatus Midichloria mitochondrii", an endosymbiont of the tick 
Ixodes ricinus with a unique intramitochondrial lifestyle. Int J Syst Evol Microbiol 2006, 56:2535-2540.

7. Sacchi L, Bigliardi E, Corona S, Beninati T, Lo N, Franceschi A: A symbiont of the tick Ixodes ricinus invades and consumes mitochondria in a mode similar to that of the parasitic bacterium Bdellovibrio bacteriovorus. Tissue Cell 2004, 36:43-53.

8. Epis S, Mandrioli M, Genchi M, Montagna M, Sacchi L, Pistone D, Sassera D: Localization of the bacterial symbiont Candidatus Midichloria mitochondrii within the hard tick Ixodes ricinus by whole-mount FISH staining. Ticks Tick-Borne Dis 2013, 4:39-45.

9. Epis S, Sassera D, Beninati T, Lo N, Beati L, Piesman J, Rinaldi L, McCOY KD, Torina A, Sacchi L, Clementi E, Genchi M, Magnino S, Bandi C: Midichloria mitochondrii is widespread in hard ticks (Ixodidae) and resides in the mitochondria of phylogenetically diverse species. Parasitology 2008, 135:485-494.

10. Dergousoff SJ, Chilton NB: Novel genotypes of Anaplasma bovis, "Candidatus Midichloria mitochondrii" sp. and Ignatzschineria sp. in the Rocky Mountain wood tick, Dermacentor andersoni. Vet Microbiol 2011, 150:100-106.

11. Mariconti M, Epis S, Gaibani P, Dalla Valle C, Sassera D, Tomao P, Fabbi M, Castelli F, Marone P, Sambri V, Bazzocchi C, Bandi C: Humans parasitized by the hard tick Ixodes ricinus are seropositive to Midichloria mitochondrii: is Midichloria a novel pathogen, or just a marker of tick bite? Pathog Glob Heal 2012, 106:391-396.

12. Skarphédinsson S, Jensen PM, Kristiansen K: Survey of tickborne infections in Denmark. Emerg Infect Dis 2005, 11:1055-1061.

13. Mediannikov O, Ivanov LI, Nishikawa M, Saito R, Sidel'nikov I, Zdanovskaia N, Mokretsova EV, Tarasevich I, Suzuki H: Microorganism "Montezuma" of the order Rickettsiales: the potential causative agent of tick-borne disease in the Far East of Russia. Zh Mikrobiol Epidemiol Immunobiol 2003, 7:13.

14. Bazzocchi C, Mortarino M, Grandi G, Kramer LH, Genchi C, Bandi C, Genchi M, Sacchi L, McCall JW: Combined ivermectin and doxycycline treatment has microfilaricidal and adulticidal activity against Dirofilaria immitis in experimentally infected dogs. Int J Parasitol 2008, 38:1401-1410.

15. Wang HY, Tsai MP, Tu MC, Lee SC: Universal primers for amplification of the complete mitochondrial 125 rRNA gene in vertebrates. Zool Stud-Taipei 2000, 39:61-66.

16. Edgar RC: MUSCLE: multiple sequence alignment with high accuracy and high throughput. Nucleic Acids Res 2004, 32:1792-1797.

17. Gouy M, Guindon S, Gascuel O: SeaView Version 4: a multiplatform graphical user interface for sequence alignment and phylogenetic tree building. Mol Biol Evol 2010, 27:221-224.

18. Mariconti M, Epis S, Sacchi L, Biggiogera M, Sassera D, Genchi M, Alberti E, Montagna M, Bandi C, Bazzocchi C: A study on the presence of flagella in the order Rickettsiales: the case of "Candidatus Midichloria mitochondrii. Microbiology 2012, 158:1677-1683.

19. Capelli G, Ravagnan S, Montarsi F, Ciocchetta S, Cazzin S, Porcellato E, Babiker AM, Cassini R, Salviato A, Cattoli G, Otranto D: Occurrence and identification of risk areas of Ixodes ricinus-borne pathogens: a costeffectiveness analysis in north-eastern Italy. Parasit Vectors 2012, 5:61.

20. Porretta D, Mastrantonio V, Amendolia S, Gaiarsa S, Epis S, Genchi C, Band C, Otranto D, Urbanelli S: Effects of global changes on the climatic niche of the tick Ixodes ricinus inferred by species distribution modelling. Parasit Vectors 2013, 6(1):271.

21. Cringoli G, Otranto D, Testini G, Buono V, Di Giulio G, Traversa D, Lia R, Rinaldi L, Veneziano V, Puccini V: Epidemiology of bovine tick-borne diseases in southern Italy. Vet Res 2002, 33:421-426.

22. Rinaldi L, Otranto D, Veneziano V, Milillo P, Buono V, lori A, Giulio GD, Cringoli G: Cross-sectional survey of ticks (Acari: Ixodidae) in sheep from an area of the southern Italian Apennines. Exp Appl Acarol 2004, 33:145-151.

23. Dumler J, Walker D: Order II. Rickettsiales Gieszczykiewicz 1939, 25AL emend. In Bergey's manual of systematic bacteriology. 2nd edition. Edited by Garrity G, Brenner D, Krieg N, Staley J. New York: Springer-Verlag; 2005:96-160.

24. Stibrániová I, Lahová M, Bartíková P: Immunomodulators in tick saliva and their benefits. Acta Virol 2012, 57:200-216.

\section{doi:10.1186/1756-3305-6-350}

Cite this article as: Bazzocchi et al:: Molecular and serological evidence for the circulation of the tick symbiont Midichloria (Rickettsiales: Midichloriaceae) in different mammalian species. Parasites \& Vectors 2013 6:350

\section{Submit your next manuscript to BioMed Central and take full advantage of:}

- Convenient online submission

- Thorough peer review

- No space constraints or color figure charges

- Immediate publication on acceptance

- Inclusion in PubMed, CAS, Scopus and Google Scholar

- Research which is freely available for redistribution 